\title{
Limestone caves and the Quaternary record of terrestrial tetrapods on islands
}

\author{
Donald A. McFarlane
}

McFarlane, D.A. Limestone caves and the Quaternary record of terrestrial tetrapods on islands. Scripta Geologica, 143: 23, Leiden, May 2011.

Donald A. McFarlane, Wm. Keck Science Center, The Claremont Colleges, Claremont, California 91711, U.S.A. (dmcfarlane@jsd.claremont.edu).

The potential for finding Quaternary tetrapod fossils on islands is governed by issues of biodiversity, geology, fossil preservation and timespan of records. Islands with extensive limestone exposures are particularly well represented at low and middle latitudes, where biodiversity is potentially high, and the caves and karst fissures in these landscapes have proven to be vital reliquaries of the Quaternary fossil record. This is particularly apparent when we contrast limestone islands with volcanic islands in the Lesser Antilles; the latter present a serious deficiency in the fossil vertebrate record and an impediment to understanding the biogeography of the region.

Climate has a significant impact on cave fossil preservation. Fossils are more frequently preserved in caves and fissures subject to arid or highly seasonal climates. Yearround rainfall such as occurs above the extensive cave systems of northwest Borneo is generally less conducive to preservation. Caves and karst fissures are also ephemeral on geological timescales, and few tropical island sites are known that are older than Last Interglacial. In Britain, important cave sites of Middle Pleistocene age are known, but are rare.

Quaternary cave fossil sites provide both opportunities and challenges for absolute dating. Cave and fissure stratigraphy is rarely simple and commonly violates the Principle of Superposition. However, collagen preservation in the cool caves of Britain or the dry caves of the Mediterranean islands is often very good, facilitating direct, high precision radiocarbon dating of Late Pleistocene and Holocene specimens. The frequent abundance of autochthonous calcite speleothem in known stratigraphic relationship to cave vertebrate material provides the opportunity for U-Th disequilibrium dating, with precision that now rivals radiocarbon. Recent advances in the use of laser ablation ICPMS analysis of uranium uptake profiles coupled with diffusion modeling has great promise for high-precision U-Th dating of fossil teeth from key cave sites. Finally, we are seeing the application of ${ }^{10} \mathrm{Be} /{ }^{26} \mathrm{Al}$ cosmogenic isotope dating to determining the ages of Middle Pleistocene sediments washed into caves with their entrained fossil record.

The karst record of Quaternary island vertebrates has been accumulating in collections and in print since the $19^{\text {th }}$ Century, and has provided magnificent insights into the evolutionary history of these islands and their fauna that is largely unobtainable from non-karst contexts. Nevertheless, caves and karst fissures are a distinctly finite resource, and conservation of existing sites together with procedures to identify and protect newly discovered localities are essential. 